\title{
Development of Steel Slag-Based Solidification/Stabilization Materials for High Moisture Content Soil
}

\author{
Yu Jia ${ }^{1}$, Sudong Hua ${ }^{1, *}$, Liying Qian ${ }^{2}$, Xiaojian Ren ${ }^{2}$, Jie Zuo ${ }^{3}$ and Yanfang Zhang ${ }^{3}$ \\ ${ }^{1}$ College of Materials Science and Engineering, Nanjing Tech University, Nanjing, 210009, China \\ ${ }^{2}$ Jangsu Yonggang Group Co., Ltd., Suzhou, 215628, China \\ ${ }^{3}$ China Construction Installaction Engineering Co., Ltd., Nanjing, 210023, China \\ ${ }^{*}$ Corresponding Author: Sudong Hua. Email: huasudong@126.com \\ Received: 29 March 2021 Accepted: 18 May 2021
}

\begin{abstract}
To solve the problems of high moisture content, high viscosity, and poor engineering mechanical properties of soil, this paper using with steel slag (SS) and desulfurization ash (DS) as initial raw materials, realizing the cooperative treatment of solid waste and solidification of silt soil. The synergistic utilization of SS and DS can reduce the production cost of curing agent and promote its own consumption. According to blended cement of various SS contents and inspected compressive strength performances, the most suitable raw materials ratio was selected. The best formula for this curing agent is cement:steel slag = 3:7 with 5\% DS, and its 28-day compressive strength can reach $30 \mathrm{MPa}$. The experiment shows that the effect of $\mathrm{DS}$ and $\mathrm{Na}_{2} \mathrm{SO}_{4}$ reagent with the same quality on early compressive strength improvement of cement and SS system is not much different. In this study, the mineral composition and microstructure of different gel system blocks were characterized by XRD, SEM and EDX, and a large number of webbed structures were found in the SEM test, which was not seen in previous studies. Besides, unconfined compressive strength (UCS), water resistance, and toxic characteristic leaching procedure (TCLP) were used to evaluate silt solidified soil properties. The results demonstrated that the solidified silt could meet not only the standard of general subgrade; but also has a partial stabilization effect of heavy metal ions.
\end{abstract}

\section{KEYWORDS}

Steel slag; desulfurization ash; high moisture content soil; synergistic effect; strength; stabilized soil

\section{Introduction}

Steel slag (SS) is solid wastes from either iron conversion into steel in a basic oxygen furnace; or scrap melting into steel in an electric arc furnace [1]. In China, green development is strongly advocated and supervised nowadays, and all kinds of wastes should be comprehensively utilized as far as possible. As known, SS has been declared a useful construction material, not an industrial waste, by most developed countries [2]. There has been a considerable number of studies on the resource utilization of SS, in many aspects, such as road engineering [3], aggregate in concrete [4], adsorption of metal ions in waste-water treatment $(\mathrm{Cr}, \mathrm{Cu}, \mathrm{Ni}$, etc.) [5], and a soil amendment in agriculture [6], and it has recently been investigated as a $\mathrm{CO}_{2}$ storage material [7]. However, large-scale SS utilization is now found road engineering and cement concrete, with a current utilization rate of SS no more than $40 \%$ in China, far 
behind the developed countries. Therefore, exploring more approaches to dealing with SS is highly required. Flue gas desulfurization is one of the most widely-used technologies to reduce sulfur oxide emissions, and these technologies are commonly classified as wet, semi-dry, or dry processes [8,9]. The powdered solid waste is produced in the DS of desulfurization process in steel plants and power plants. As DS contains unstable $\mathrm{CaSO}_{3} \cdot 1 /{ }_{2} \mathrm{H}_{2} \mathrm{O}$ components, few scholars have researched using of such DS and have achieved some results. Feng et al. [10] concluded that DS utilization to prepare grouting fire prevention material was environmentally friendly, and they confirmed the feasibility and effectiveness of removing chromium and vanadium from vanadium industrial wastewater using DS [11]. Navarrete et al. [12] showed that using DS is harmless in cement-based mixtures from a durability perspective, without impact on mechanical performance. As for DS used in this paper, it is produced by dry desulfurization of sodium bicarbonate. This desulfurization method is usually utilized in coke ovens, gas boilers, heating furnaces and other flue gas with low sulfur content. This kind of DS contains more sodium sulfate $\left(\mathrm{Na}_{2} \mathrm{SO}_{4}\right)$, usually directly disposed of in landfills due to high recovery costs with advanced technology, implying the limited research on this subject. Although the annual production of this type of DS is less than that of other types, the long-term stacking treatment can also pollute the ecological environment, so using DS is worth studying.

Nowadays, high-water-content soil is extensively produced from construction activities and dredging operations [13], facing major challenges to be disposed of due to environmental and regulatory issues can be solved. Several researchers have recently studied the solidification of high moisture content soils by adding additives such as cement, lime, and fly ash [14]. For instance, Xin et al. [15] studied the effect of several cement mixes on the solidification of silt, suggesting that mayenite and sulfoaluminate cement are effective components in solidifying of sewage sludge. Jongpradist et al. [16] proposed that fly ash's efficiency depends on the portion of cement, disposed of fly ash, and water content in mixtures. The strength of cement-fly ash admixed clay at high water content increased with increasing cementitious material content and duration of the curing time and decreased with increasing water content. Bayesteh et al. [17] studied that adding 20\% stone powder eliminated the adverse effects of water to increase soilcrete strength in marine clay/sand that maintains grout workability. Furthermore, several fiber kinds including natural fibers (i.e., jute, wheat straw, rice straw, corn silk, coir fiber, etc.) and synthetic fibers (i.e., nylon fiber, polypropylene fiber, polyester fiber, PET fiber, glass, etc.) have been used to treat high moisture content soil [13,18-21]. Nevertheless, from environmental protection and economy perspective, natural fibers have broad application as they are inexpensive, plentiful, and low dense and also cause an increase in organic matter in soil, affecting the solidification process, but they have no similar environmental risk as inorganic materials. Besides, the strength of solidified silt is not high in most of the current studies due to cost limitation, so it is necessary to develop a cheap and effective silt curing agent.

The chemical composition and mineral composition of SS are similar to Portland cement clinker, composing some cement clinker minerals, such as $\mathrm{C}_{3} \mathrm{~S}, \mathrm{C}_{2} \mathrm{~S}, \mathrm{C}_{3} \mathrm{~A}$, and $\mathrm{C}_{4} \mathrm{AF}$ [22]. Therefore, it has a certain degree of hydration activity that keeps it in a state of expansion for a long time. This feature makes it a greater hidden danger in the construction field, but it is harmless when used in soil. SS has been used in soil subgrade for decades in developed countries and previous studies demonstrated that SS has adsorption effect on contaminated soil [23-25]. However, few studies are found on SS use in silty soil solidification, because SS has only weak pozzolanic reactivity, so its solidification ability in soils with high moisture content is feeble. Given this, it is necessary to cooperate with other materials to make SS solidified silt as a roadbed. Meanwhile, this kind of steel slag-based hardener will have a good effect on solidifying contaminated soil, which is also studied in this paper.

The use of SS to partially replace cement to prepare steel slag-based material and application of DS as the activator saves costs, reduces $\mathrm{CO}_{2}$ emissions and also solves the challenging problem of using SS for long-term expansion, because there is much space in the soil to accommodate SS expansion. 
Simultaneously, it provides a way to utilize this kind of DS, and the combination of the two substances also realizes the cooperative treatment of solid waste. Many studies have shown that $\mathrm{Na}_{2} \mathrm{SO}_{4}$ (the main component of DS used herein) has some stimulating effects on cement and steel slag. Thus, the paper examines the influence of $\mathrm{DS}$ and $\mathrm{Na}_{2} \mathrm{SO}_{4}$ reagents as activators on the strength and structural properties of cementitious materials composed of SS and cement. The curing properties of the curing agent for high moisture content soil were evaluated. Meanwhile, the compounds formed and their stability are also discussed after $\mathrm{Cu}$ and $\mathrm{Cr}$ removal from soil are removed under different curing agent content.

\section{Materials and Methods}

\subsection{Materials}

The SS was supplied from the Masteel Group in Anhui province of China. Fig. 1 shows the particle size distribution of SS obtained using a Malvern Mastersizer 2000 laser diffractometer. Specifically, it indicates a bimodal and wide distribution diagram, basically between 5 and $50 \mu \mathrm{m}$. The DS was provided by Jiangsu Nangang Group Co., Ltd., China; cement, grade 42.5 ordinary Portland cement; $\mathrm{Na}_{2} \mathrm{SO}_{4}$, as an analytical reagent (content $\geq 99 \%$ ). Tab. 1 shows the chemical compositions of steel slag (SS), cement, and desulfurization ash (DS).

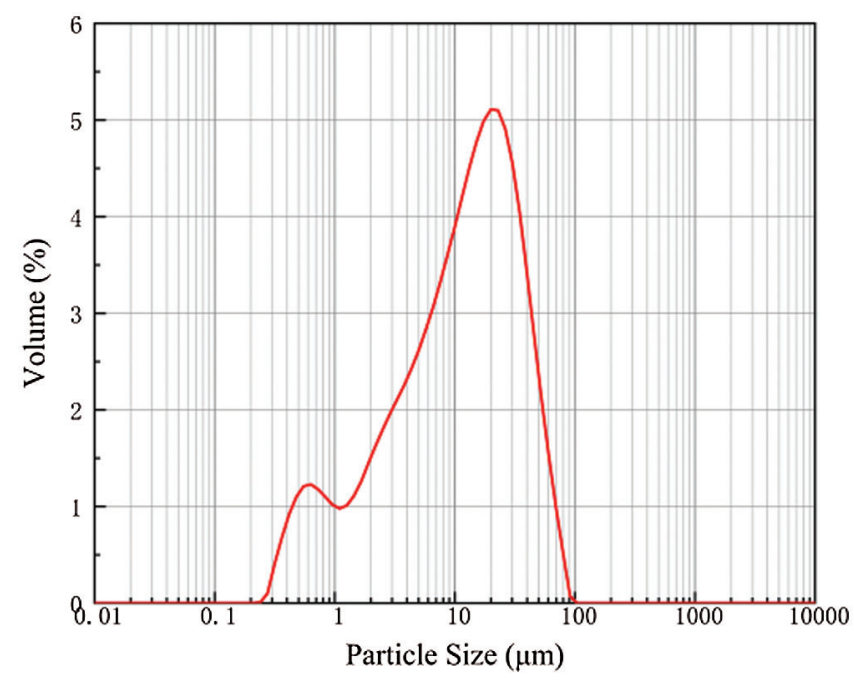

Figure 1: Particle size distribution of SS

Table 1: Chemical compositions of raw materials

\begin{tabular}{llllllllll}
\hline Material & $\mathrm{SiO}_{2}$ & $\mathrm{Al}_{2} \mathrm{O}_{3}$ & $\mathrm{CaO}$ & $\mathrm{Fe}_{2} \mathrm{O}_{3}$ & $\mathrm{Na}_{2} \mathrm{O}$ & $\mathrm{SO}_{3}$ & $\mathrm{MgO}$ & $\mathrm{TiO}_{2}$ & LOI \\
\hline Steel slag & 11.22 & 2.54 & 48.52 & 25.17 & - & - & 4.16 & 1.33 & 1.58 \\
Cement & 21.35 & 5.45 & 57.03 & 3.69 & - & 3.10 & 4.01 & 0.28 & 2.51 \\
DS & 0.02 & 0.01 & 0.33 & 0.04 & 43.91 & 51.89 & - & - & 2.78 \\
\hline
\end{tabular}

As shown in Tab. 2, the physical characteristics of original soil were determined by the standard GB/T 50123-1999 (in Chinese). The contaminated soil was prepared in laboratory, and the original soil was taken from the silt soil along the rainy banks of the Yangtze River. A certain amount of $\mathrm{Cu}\left(\mathrm{NO}_{3}\right)_{2}$ and $\mathrm{K}_{2} \mathrm{Cr}_{2} \mathrm{O}_{7}$ solutions were added to the muddy soil, mixed evenly with a blender, and then placed in a plastic bucket with a lid for 7 days, so that the heavy metal ions could infiltrate into the soil particles completely. After 
that, the soil was dried in a $60^{\circ} \mathrm{C}$ oven and then crushed through a 60 -mesh sieve. To facilitate the sample preparation for compaction and strength tests [26], water was added to produce the best moisture content $(20 \%)$ in the blender, first slow for $1 \mathrm{~min}$ and then fast for $2 \mathrm{~min}$, to ensure the uniformity of contaminated soil.

Table 2: Basic physical properties of silty soil

\begin{tabular}{lllllll}
\hline $\begin{array}{l}\text { Basic } \\
\text { nature }\end{array}$ & $\begin{array}{l}\text { Specific } \\
\text { gravity }\end{array}$ & $\begin{array}{l}\text { Liquid } \\
\text { limit }(\%)\end{array}$ & $\begin{array}{l}\text { Plastic } \\
\text { limit }(\%)\end{array}$ & $\begin{array}{l}\text { Initial water } \\
\text { content }(\%)\end{array}$ & $\begin{array}{l}\text { Optimum moisture } \\
\text { content }(\%)\end{array}$ & $\begin{array}{l}\text { Density } \\
\left(\mathrm{g} / \mathrm{cm}^{3}\right)\end{array}$ \\
\hline Value & 2.73 & 38 & 23.5 & 51.6 & 20 & 1.81 \\
\hline
\end{tabular}

\subsection{Mixture Proportions and Preparation}

The experiment was mainly divided into two parts. In the first part, the performance test and mechanism analysis of the paste block is done. The cement and SS were prepared with different ratios of 9:1, 7:3, 5:5, $3: 7$, and 1:9 to select the best formula, which was then mixed with $1 \%, 3 \%, 5 \%, 7 \%, 9 \%$ DS to prepare blocks, and $5 \% \mathrm{Na}_{2} \mathrm{SO}_{4}$ was made as a comparison sample. The designs and water/solid ratios of mixture are illustrated in Tab. 3. The gelation block was prepared by vibration forming method. All raw materials were mixed in a pan mixer at different water/solid ratios under standard consistency (ISO 9597:2008). The stirred paste was then poured into a $40 \mathrm{~mm} \times 40 \mathrm{~mm} \times 40 \mathrm{~mm}$ plastic mold, forming two vibration moldings to minimize bubbles' impact. These samples were demolded after $24 \mathrm{~h}$ of curing. Subsequently, the specimens were cured at $20 \pm 1{ }^{\circ} \mathrm{C}$ and $>98 \%$ humidity for 3,7 , and 28 days, respectively [27]. All specimens were prepared and maintained with reference to standard (GB/T 50081-2002).

Table 3: Mixture proportions of samples

\begin{tabular}{lccccc}
\hline Sample & Cement $/ \%$ & $\mathrm{SS} / \%$ & $\mathrm{DS} / \%$ & $\mathrm{Na}_{2} \mathrm{SO}_{4} / \%$ & Water/solid \\
\hline $\mathrm{A} 1$ & 100 & 0 & 0 & 0 & 0.330 \\
$\mathrm{~A} 2$ & 90 & 10 & 0 & 0 & 0.324 \\
$\mathrm{~A} 3$ & 70 & 30 & 0 & 0 & 0.312 \\
$\mathrm{~A} 4$ & 50 & 50 & 0 & 0 & 0.300 \\
$\mathrm{~A} 5$ & 30 & 70 & 0 & 0 & 0.288 \\
$\mathrm{~A} 6$ & 10 & 90 & 0 & 0 & 0.276 \\
$\mathrm{~A} 7$ & 30 & 70 & 1 & 0 & 0.288 \\
$\mathrm{~A} 8$ & 30 & 70 & 3 & 0 & 0.288 \\
$\mathrm{~A} 9$ & 30 & 70 & 5 & 0 & 0.288 \\
$\mathrm{~A} 10$ & 30 & 70 & 7 & 0 & 0.288 \\
$\mathrm{~A} 11$ & 30 & 70 & 9 & 0 & 0.288 \\
$\mathrm{~A} 12$ & 30 & 70 & 0 & 5 & 0.288 \\
\hline
\end{tabular}

The selected curing agent was added to the contaminated soil at the dosage of $3 \%, 5 \%, 7 \%$, and $9 \%$. The mixed contaminated soil was put into a $\Phi 50 \mathrm{~mm} \times 50 \mathrm{~mm}$ metal mold, then press molded with a hydraulic jack. After preparing the stabilized soil, it was put into a sealed bag and then placed in a curing box with a constant temperature of $20^{\circ} \mathrm{C}$ for 3,7 , and 28 days. 


\subsection{Test Methods}

\subsubsection{Compressive Strength}

The compressive strength of gelation blocks was measured using a pressure testing machine with a loading rate of $100 \mathrm{kN} / \mathrm{s}$ when the curing time was 3, 7, and 28 days. Three samples were measured for each set of data, and the average value was taken. The data with significant deviation should be discarded. Some of the tested samples were dipped into industrial alcohol for microscopic analysis of the specific curing time.

\subsubsection{Unconfined Compressive Strength (UCS)}

The UCS test is divided into two parts: one part is the sample after curing to the corresponding age, the other part is the sample after curing and then immersed in water. The strength of all solidified soil samples was measured based on UCS tests. The UCS tests were carried out on related specimens using ASTM-D 2166 standard [28].

\subsubsection{Water Resistance}

The stabilized soil samples for 7 and 28 days were taken out of the curing box and then immersed in water at $20^{\circ} \mathrm{C}$ for 3 days. Each sample is spaced $2 \mathrm{~cm}$ apart in water, and the sample surface is also $2 \mathrm{~cm}$ away from water surface. After 3 days, those samples were removed and dried with water, and then the compression test was performed on them. The water resistance is mainly evaluated by softening coefficient $\mathrm{K}$ calculated according to formula (1).

$K=\frac{P_{1}}{P_{0}}$

where $\mathrm{P}_{0}$ is UCS before immersion, and $\mathrm{P}_{1}$ is UCS after 3 days of immersion.

\subsubsection{XRD}

In this work, an X-ray diffractometer (Smartlab $3 \mathrm{KW}$ ) was employed to further identify the main crystalline phases of SS excited by DS. It was performed over a $2 \theta$ range of $5^{\circ}-80^{\circ}$ at $2.4^{\circ} / \mathrm{min}$ scanning rate. Before testing, all samples were ground, passed through a 200 mesh sieve, and then baked in an oven at $60^{\circ} \mathrm{C}$ for $6 \mathrm{~h}$.

\subsubsection{SEM}

The SEM test used ZEISS EVO MA18 to observe the surface morphology of the pastes sample and stabilized soil. For the former, slices were struck off the original with a hammer and used for testing. For the stabilized soil, small pieces needed to be pulled off by hand for testing to ensure structural integrity, rather than slicing with a knife.

\subsubsection{TCLP and $p H$}

TCLP test was conducted following USEPA Method 1311 [1]. For stabilized soil samples to be tested, the large particles were ground and then removed with a 100 mesh sieve. Diluted acetic acid ( $\mathrm{pH} 2.88 \pm 0.05)$ was used as the leaching solution with a liquid/solid ratio of 20:1. The dissolution was performed using a fliptype oscillation device at $30 \pm 2 \mathrm{rpm}$ for $18 \mathrm{~h}$. The turbid solution was first removed by filter paper and then purified filtrate was obtained by suction with a $0.45 \mu \mathrm{m}$ filter membrane. The $\mathrm{pH}$ of each prepared leach solution was tested.

\section{Results and Discussions}

\subsection{Compressive Strength and Unconfined Compressive Strength (UCS)}

The compressive strength for the binary system block is presented in Fig. 2. Viewed as a whole, the compressive strength of the paste decreases with the increasing SS content. Compared with pure cement 
paste, when SS content was $90 \%$, the strength of 28 -day decreased by about $50 \%$. This indicated that SS has certain cementitious activity, and SS block strength in the later stage was also good, reaching $30 \mathrm{MPa}$ in 28 days, more than 3 times of that in 7 days. When SS content was 10\%, the strength of 7 -day and 28-day paste was slightly higher than that of pure cement block, which may be due to small SS (38 $\mu \mathrm{m})$, playing a filling role in the paste system. It indicated that a small amount of steel slag could be added to cement to improve its strength performance and could be used as a partial substitute for cement [29].

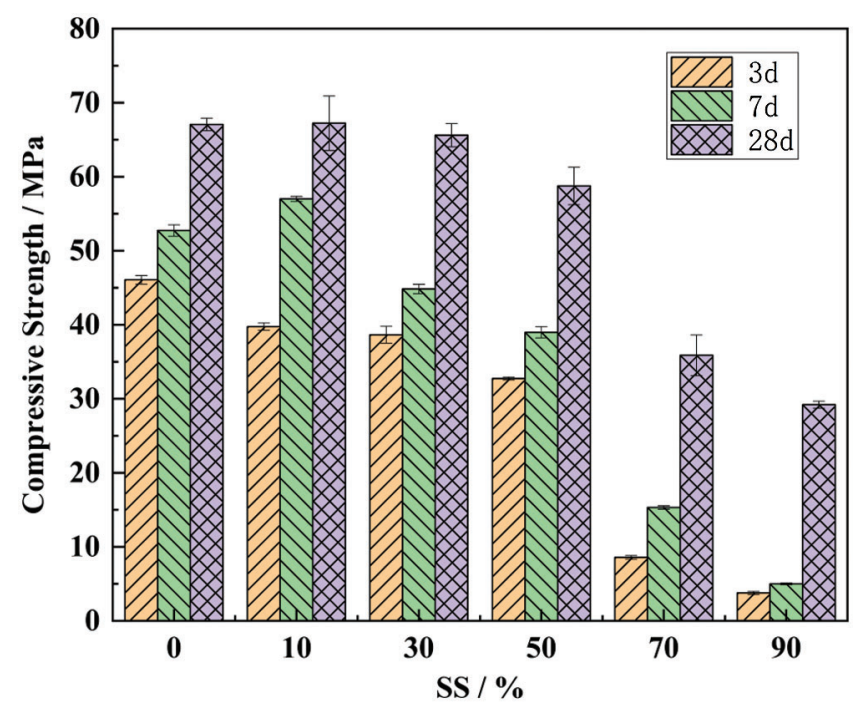

Figure 2: Compressive strength of cement and SS

It is considering that SS-based curing agent is considered to be used in solidifying polluted soil, SS, and cement needed to reach a reasonable ratio. Excessive cement content can have a good curing effect in a short period, and the solubility of the hydroxide precipitated with heavy metals in an highly acidic or alkaline environment will significantly increase, thereby affecting the curing effect [30]. Excessive SS has an excellent long-term solidification effect on heavy metals, without ideal short-term effect. It can be seen from Fig. 2 that the compressive strength at 7 and 28 days is $15 \mathrm{MPa}$ and $33 \mathrm{MPa}$, respectively, when SS content is $70 \%$, indicating that it has a good strength performance in the early stage. In addition, the excessive amount of cement would increase the cost, so the ratio of cement:SS $=30: 70$ was selected as the basic formula.

Fig. 3 displays that the compressive strength of blocks in different times was as follows: in the early 3 days and 7 days, the intensity first increased and then decreased with increasing DS content, and at 28 days, the intensity first decreases then increases and then decreases. The results evidenced that adding a small amount of DS significantly improved the initial strength of blocks. Simultaneously, a very high dosage also had a great negative impact on the strength. For the mixture of $9 \%$, its 28 -day strength was reduced by half compared with the blank sample. However, when the mixing amount is $5 \%$, the intensity of advance was the highest, and the intensity at 28 days was second only to the comparison sample, reaching $30 \mathrm{MPa}$. Therefore, the optimized formulation of cement:SS $=3: 7$ plus $5 \%$ DS was selected as the curing agent. 


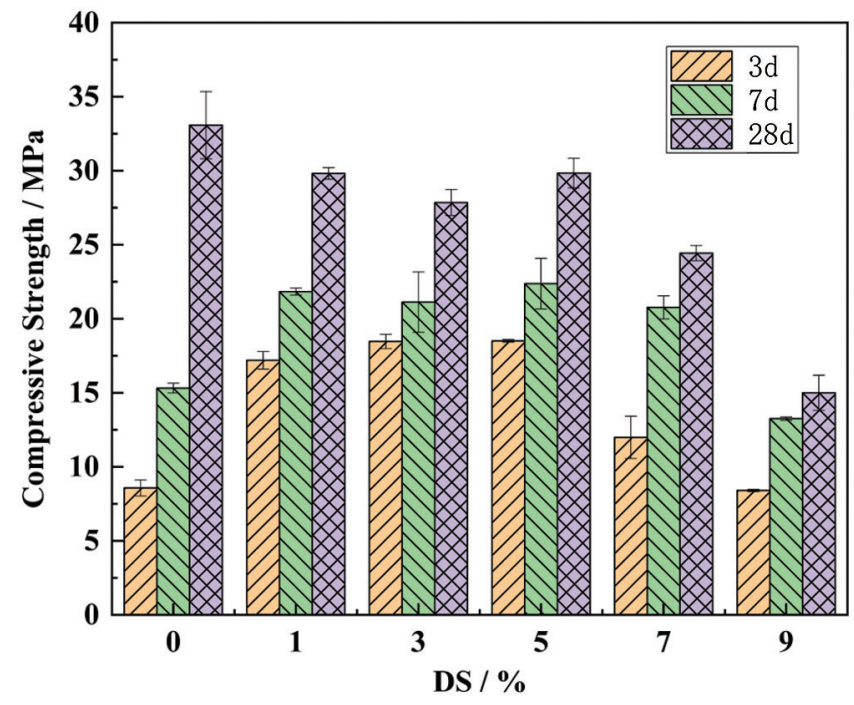

Figure 3: Effect of DS content on the strength of the basic formula

Fig. 4 shows the influence of 5\% sodium sulfate and DS on the compressive strength of the pure slurry. Compared with the samples mixed with $\mathrm{Na}_{2} \mathrm{SO}_{4}$, the compressive strength of the samples mixed with DS at 3 and 7 days was slightly lower, but the strength at 28 days was slightly higher. The results show that DS effect on steel slag-based clean slurry is similar to that of sodium sulfate under the same mass. However, using DS can not only save costs but also lead to beneficial utilization of solid waste.

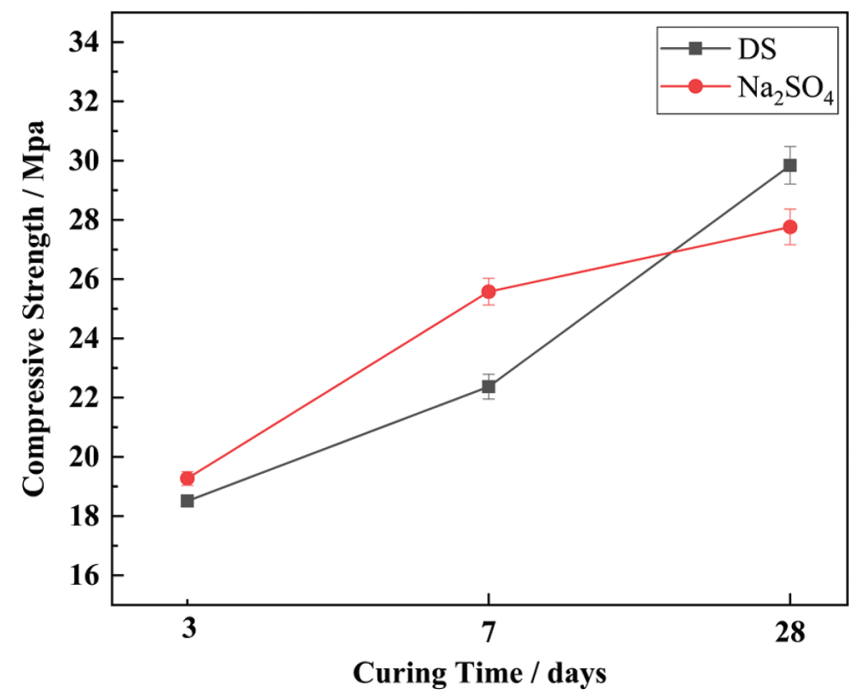

Figure 4: Influence of different activators on compressive strength

Fig. 5 showcases that the UCS of different doses of optimized curing agents added to contaminated soil. When the cementitious materials are added to the soil, the strength of the solidified sample is essentially improved by a series of physical and chemical reactions of the agent, and these reactions will form a skeleton in soil [31,32] and transform the soil from a soft plastic state to a solidified state [33]. Obviously, UCS increased with increasing of the dosage. Nevertheless, when the mixing amount was more than 5\%, the UCS value in 28 days was lower than in 7 days. In particular, when the dosage was 
$9 \%$, the 7-day UCS was 3.13 MPa, and the 28-day UCS was $2.71 \mathrm{MPa}$, which reduced its strength by about $13 \%$. This could be because adding a small amount of curing agent had a gelatinizing effect on the soil moisture, making the soil particles more closely related to each other and thus improved UCS. As curing agent dosage was increased, higher strength was produced with more cementitious materials. Meanwhile, the properties of cementitious materials had increasing influence on the soil. The DS influence on the block strength was increased in the early stage and decreased in the later stage. Therefore, when the dosage of the curing agent was more than 5\%, UCS of 28 days was lower than that of 7 days. In association with the cost of curing agent, curing strength and soil tolerance, $5 \%$ was the most appropriate amount.

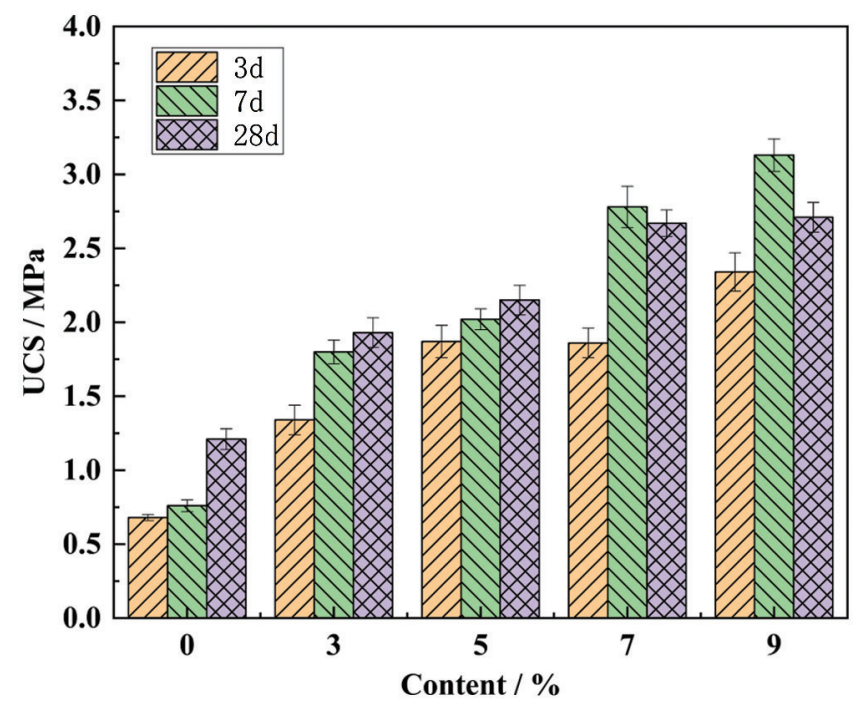

Figure 5: UCS of contaminated soil with different dosage of curing agent

\subsection{Water Resistance}

Tab. 4 shows the softening coefficient of curing agents with various soil dosages for 7 days and 28 days. The original soil without curing agent had no strength, and the sample collapsed in water after being immersed in water for 3 days after curing for 7 days and 28 days, respectively, as shown in Fig. 6. Tab. 4 displays that the softening coefficient $\mathrm{K}$ value is the largest when the curing agent content in the soil is $5 \%$, whether it is cured for 7 or 28 days. As the softening coefficient is larger, the water resistance of test is better [34], so when the curing agent content is $5 \%$, the water resistance is also the best. Besides, after 28 days of curing, the softening coefficient was $0.45,0.72,0.70$, and 0.71 , generally greater than that after 7 days of curing with $0.35,0.54,0.51$, and 0.53 values. By increasing the curing time, the curing agent reacts with soil's moisture to generate more hydration products, thus improving the sample's density and leading to water resistance improvement. Simultaneously, this good water resistance can avoid the solidified soil soaked by rain into the original high moisture content soil. 
Table 4: The softening coefficient under different dosage of curing agent

\begin{tabular}{|c|c|c|c|c|c|c|}
\hline \multirow{2}{*}{ Content $(\%)$} & \multicolumn{2}{|c|}{7 days of UCS/MPa } & \multirow[t]{2}{*}{$\mathrm{K}$} & \multicolumn{2}{|c|}{28 days of $\mathrm{UCS} / \mathrm{MPa}$} & \multirow[t]{2}{*}{$\mathrm{K}$} \\
\hline & Unsoaked & After soak $3 \mathrm{~d}$ & & Unsoaked & After soak $3 \mathrm{~d}$ & \\
\hline 0 & 0.76 & - & - & 1.21 & - & - \\
\hline 3 & 1.80 & 0.63 & 0.35 & 1.93 & 0.87 & 0.45 \\
\hline 5 & 2.02 & 1.10 & 0.54 & 2.15 & 1.55 & 0.72 \\
\hline 7 & 2.78 & 1.20 & 0.51 & 2.67 & 1.86 & 0.70 \\
\hline 9 & 3.13 & 1.66 & 0.53 & 2.71 & 1.92 & 0.71 \\
\hline
\end{tabular}

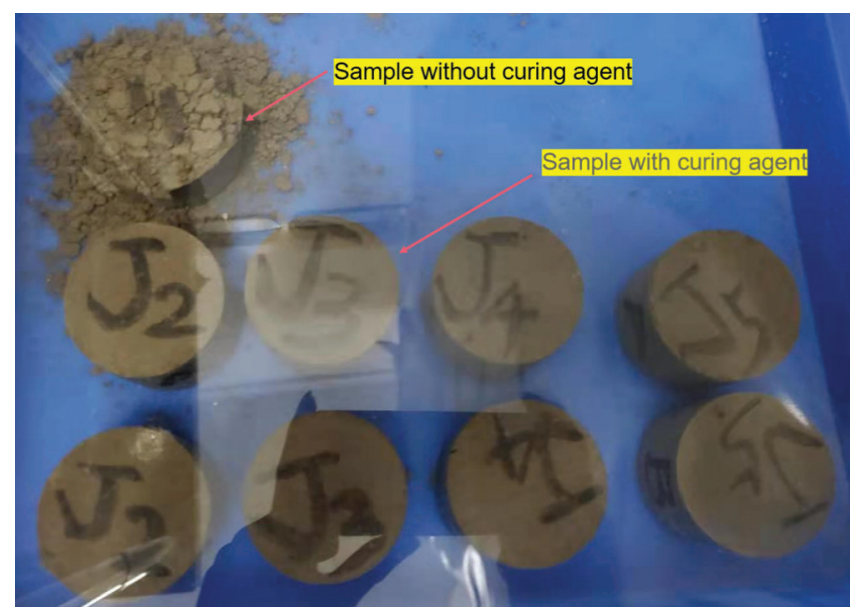

Figure 6: The 28-day sample was immersed in water for 3 days

\subsection{XRD Analysis}

XRD patterns of Sample A5 and Sample A9 (5\% DS) at 7 days and 28 days are shown in Fig. 7. The main mineral phases were $\mathrm{Ca}(\mathrm{OH})_{2}$, ettringite, and C-S-H in all samples because they were hydration products of the silicate clinker that contained C2S, C3S,C3A, and a little gypsum. Compared with Sample A5 (7 d) and A9 (7 d) regarding $\mathrm{XRD}$ analysis, the diffraction peaks of $\mathrm{Ca}(\mathrm{OH})_{2}$ was weakened in Sample A5 (28 d) and A9 (28 d). This indicated that the $\mathrm{Ca}(\mathrm{OH})_{2}$ had a further reaction or a microscopic morphology transformation in the later hydration process. Sample A9 (7 d) exhibited a stronger diffraction peak intensity of ettringite than sample A5 (7 d). The results indicated that sodium sulfate brought by DS reacted with the hydration product calcium hydroxide, forming calcium sulfate and sodium hydroxide. More gypsum could provide more $\mathrm{SO}_{4}{ }^{2-}$, promoting its reaction with $\mathrm{C} 3 \mathrm{~A}$, resulting in faster ettringite formation. More gypsum provides more sulfate ions, enabling its reaction with calcium aluminate, resulting in faster ettringite formation. This also stabilized the microstructure earlier, and a large ettringite amount acted as a coagulant in the structure, binding the various large particles of polymer together and improved the compressive strength of the sample. The analysis of XRD was consistent with the results of previous compressive strength experiments. In addition, the presence of $\mathrm{C} 2 \mathrm{~S}$ and $\mathrm{Ca}_{2} \mathrm{Fe}_{2} \mathrm{O}_{5}$ in Fig. 7 is also critical to the solidification of heavy metals because they can react with heavy metal ions. The reaction equations were as follows:

$$
\mathrm{Ca}_{2} \mathrm{Fe}_{2} \mathrm{O}_{5}+\mathrm{M}^{2+} \rightarrow \mathrm{M}_{2} \mathrm{Fe}_{2} \mathrm{O}_{5}+\mathrm{Ca}^{2+} \quad(\mathrm{M}=\mathrm{Pb}, \mathrm{Cu}, \mathrm{Cd})
$$




$$
\mathrm{Ca}_{2} \mathrm{SiO}_{4}+\mathrm{M}^{2+} \rightarrow \mathrm{M}_{2} \mathrm{SiO}_{4}+\mathrm{Ca}^{2+} \quad(\mathrm{M}=\mathrm{Pb}, \mathrm{Cu}, \mathrm{Cd})
$$

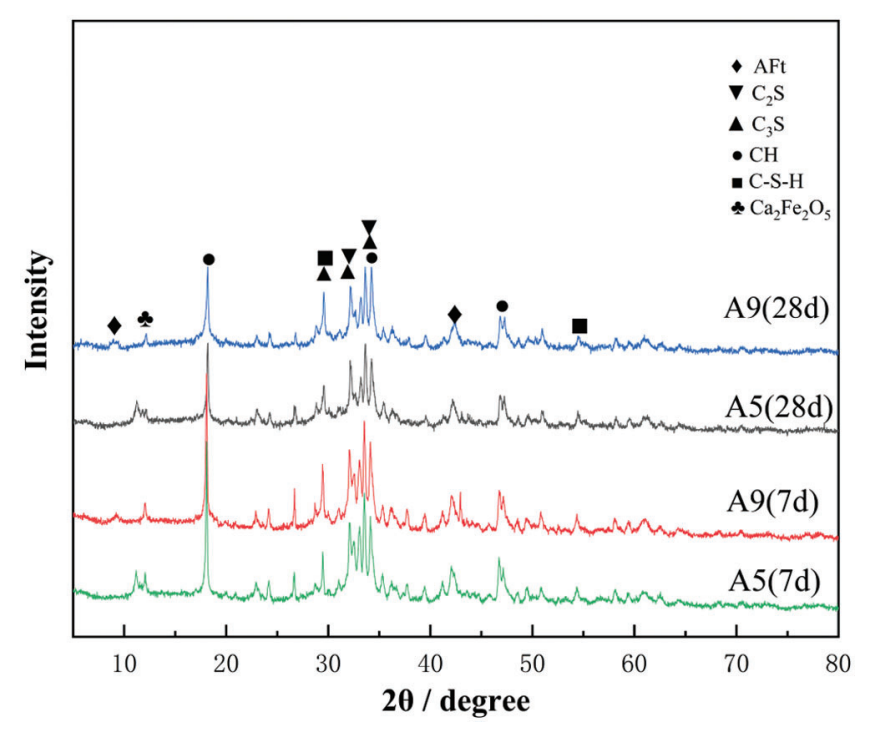

Figure 7: XRD of samples with different DS content

\subsection{SEM and EDX Analysis of Blocks}

The microstructural characteristics of Sample A5 and Sample A9 (5\% DS) at 28 days were shown in Fig. 8. The EDX analysis of the selected area for blocks was shown in Fig. 8. From the EDX analysis of Point 1 and Point 2 in the similar substance was mainly composed of $\mathrm{O}$ and $\mathrm{Ca}$ elements, which can be identified as hydration SS products, rather than obviously identified cement hydration products such as C$\mathrm{S}-\mathrm{H}$ and AFt. On the other hand, there is a large amount of webbed substance in Figs. $8 \mathrm{a}$ and 8b, and the length is more than $10 \mu \mathrm{m}$, and a large area of the sample is covered. In the common cement system, ettringite is mainly in the form of a needle and stick, and these ettringite crystals are usually in the form of radial [35], circular [36], spherical [37], six-sided needle-like [38], or massive ettringite clusters. So even though ettringite has many different forms, it does not have a consistent structure. Simultaneously, the amount of webbed material was much greater than that of ettringite in pure cement paste. The webbed substance may be formed by the simultaneous hydration of SS and cement in the later period. As Fig. 8b shows, part of the webbed material grew out of the material at Point 2. Combined XRD and EDX analyses, the Point 2 region may be $\mathrm{Ca}(\mathrm{OH})_{2}$, while the Point 1 region is an unknown substance with $\mathrm{Ca}(\mathrm{OH})_{2}$ as the primary reactant. This webbed structure connects most of the material in the slurry, making the structure more compact and improving overall performance, consistent with the compressive strength results.

From EDX analysis of Point 3, Fig. 8 shows that the irregular cuboid substance of Point 3 was mainly composed of $\mathrm{O}, \mathrm{Ca}, \mathrm{Al}, \mathrm{S}$, and Fe elements, which can be identified as SS particles [27]. Fig. 9d manifests that the complicated substance of Point 4 was generally composed of $\mathrm{O}, \mathrm{Ca}, \mathrm{Na}, \mathrm{Al}$, and $\mathrm{S}$ elements which could be $\mathrm{NaOH}, \mathrm{AFt}, \mathrm{Ca}(\mathrm{OH})_{2}$ and $\mathrm{C}-\mathrm{S}-\mathrm{H}$. This is because after adding $5 \% \mathrm{DS}, \mathrm{SO}_{4}{ }^{2-}$ can be increased faster due to the high solubility of sodium sulfate in it, and ettringite can be directly generated, which avoids the mutual conversion process between substances improving the early strength of cement paste. Simultaneously, as calcium sulfate solubility is less than that of calcium hydroxide, adding $\mathrm{Na}_{2} \mathrm{SO}_{4}$ further increases the reaction pathway of $\mathrm{Ca}(\mathrm{OH})_{2}$, generating $\mathrm{CaSO}_{4}$ and $\mathrm{NaOH}$. Fig. $8 \mathrm{~d}$ demonstrates that the obvious cementitious-like substance is $\mathrm{C}-\mathrm{S}-\mathrm{H}$ gel, which is the cement and SS hydration product at various ages. It can continuously improve structure density and is also one of the most essential substances to support the sample strength. 

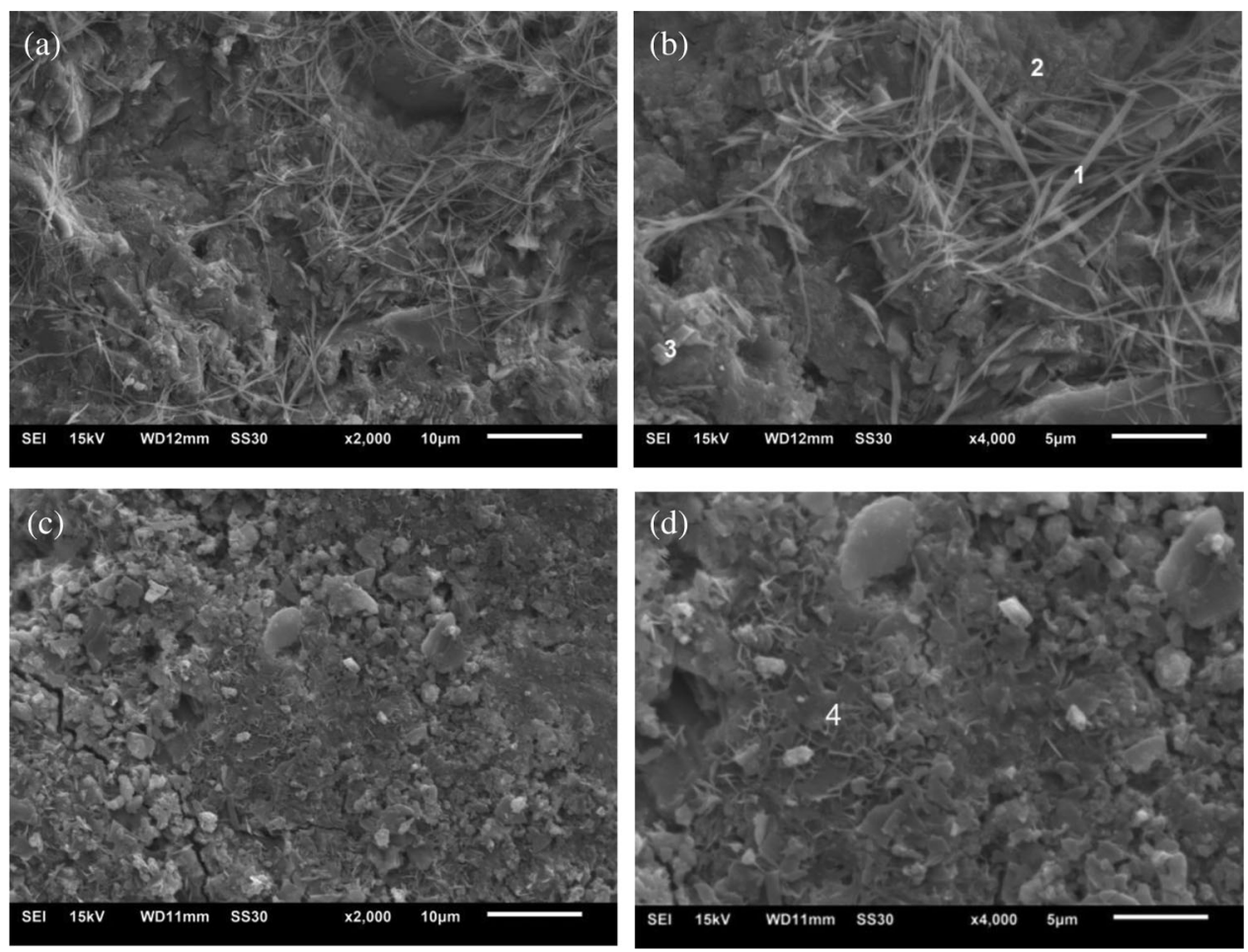

Figure 8: 28-day microscopic morphology of blocks. (a) Sample A5 $\times 2000$. (b) Sample A5 $\times 4000$. (c) Sample A9 × 2000. (d) Sample A9 × 4000
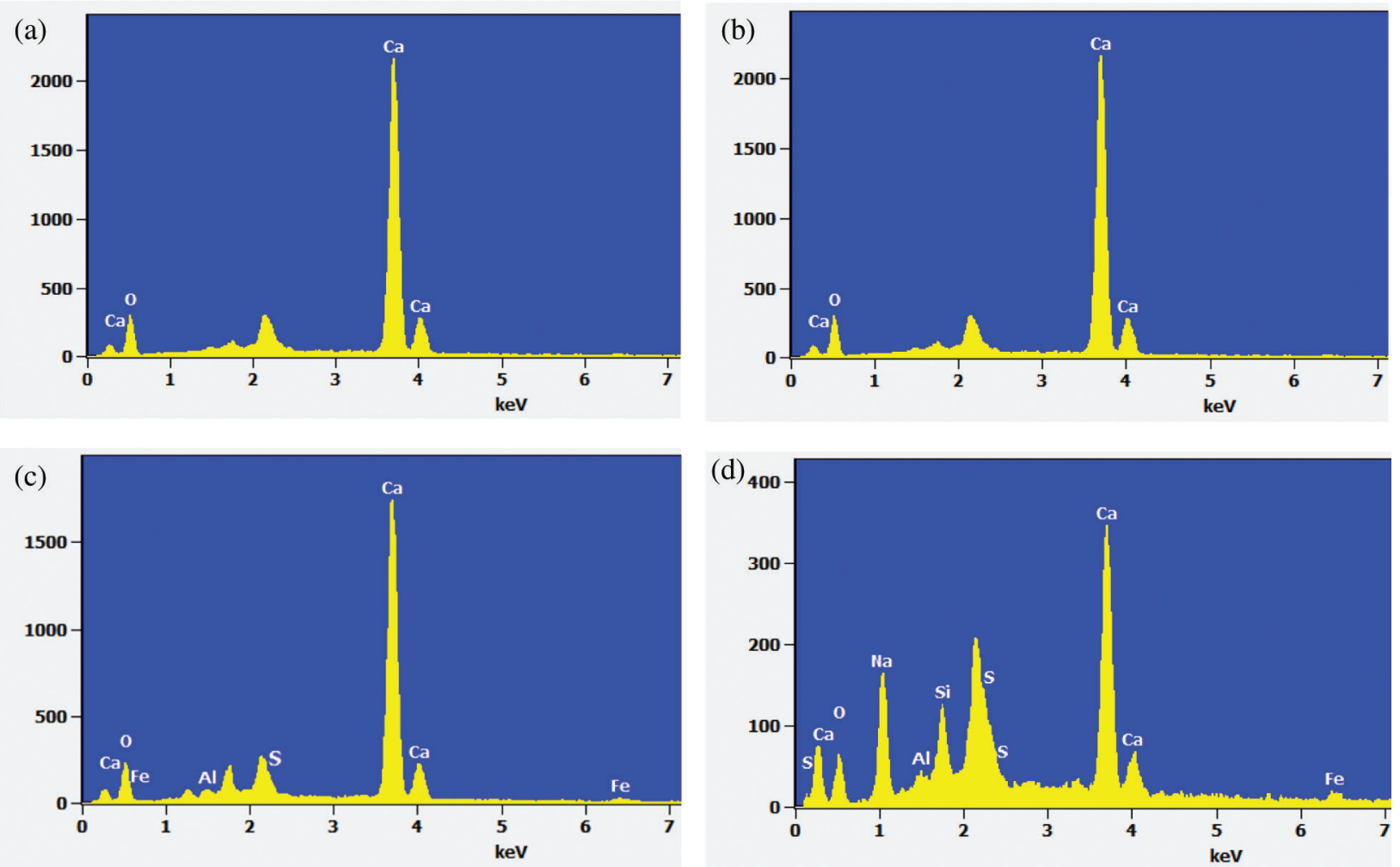

Figure 9: EDX analysis results of selected points. (a) EDX analysis of Point 1. (b) EDX analysis of Point 2. (c) EDX analysis of Point 3. (d) EDX analysis of Point 4 
Compared with Fig. 8a, the surface of Fig. 8c is not only free of webbed substances but also contains tiny cracks, which reduces the sample integrity, consistent with the previous decrease in compressive strength. However, Fig. 8d indicates that there are more flaky structures, and the overall surface area is larger, which increases the contact surface with soil particles, thus improving the curing effect of cementitious materials.

\subsection{TCLP and pH Analysis}

Fig. 10 shows $\mathrm{Cu}^{2+}$ and $\mathrm{Cr}^{6+}$ concentrations in the soil leaching solution and the leaching solution's $\mathrm{pH}$ value after the heavy metal contaminated soil was solidified with SS curing agent of 3\%, 5\%, 7\% and 9\% for 28 days. $\mathrm{Cu}^{2+}$ concentration decreased with increasing the curing agent; for instance, when dosage is $9 \%$, $\mathrm{Cu}^{2+}$ concentration decreased by $69 \%$ compared with that of the blank sample. Meanwhile, $\mathrm{Cr}^{6+}$ concentration increased adding the curing agent. This may be because with the increase of curing agent content, soil alkalinity was improved, and part of $\mathrm{Cr}^{3+}$ was oxidized into $\mathrm{Cr}^{6+}$. Although the harm of $\mathrm{Cr}^{6+}$ was more than 10 times that of $\mathrm{Cr}^{3+}$, the overall leaching ion concentration was still very low, which fully meets China's “Grade III Soil Environmental Quality Standard." The pH value of the leaching solution of contaminated soil increased with increasing the curing agent content, which also confirmed that the curing agent could provide an alkaline environment for soil.

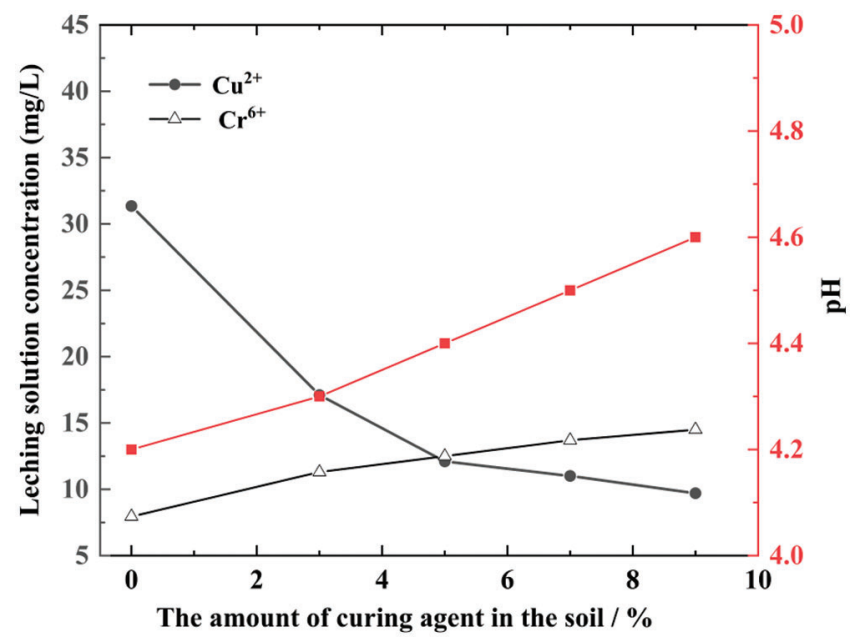

Figure 10: 28 days heavy metal leaching solution concentration and $\mathrm{pH}$

Fig. 10 shows that SS-based materials have an effective effect on heavy metals in contaminated soil. With the continuous hydration of cement and SS, the soil structure would become denser, and more metal ions can be solidified at the same time so that the solidification effect has long-term effectiveness.

\section{Conclusion}

In this paper, using SS as the main raw material and DS as activator, the curing agent not only has a lower cost but also possesses better engineering performance after curing the soil with high moisture content. Based on the results of this study, the following main conclusions can be drawn:

(1) According to the compressive strength test, cement:SS $=3: 7$ with $5 \%$ DS was selected as the formula, and DS addition can promote ettringite formation, thus improving the early strength of the sample. Compared with $\mathrm{Na}_{2} \mathrm{SO}_{4}$ reagent activator, using DS can not only enhance the early compressive strength of the curing agent slurry, but also greatly save the cost. 
(2) When the curing agent content is $5 \%$, the solidified silt has good water resistance, and its UCS meets the Chinese subgrade standard (>1.5 MPa).

(3) Through microstructure analysis, many structures appeared in the 28-day microscopic maps. After adding DS, the spiderlike structure basically disappeared, and more tiny layers were formed to bind with C-S-H gel; meanwhile, some cracks also appeared, which adversely impacted the strength.

(4) The addition of a curing agent can reduce $\mathrm{Cu}^{2+}$ leaching in soil and increase the environment's alkalinity.

Funding Statement: Funding from the Jiangsu Provincial Department of Science and Technology Key Research and Development Program (Social Development) (Grant No. BE2018697), the Demonstration Engineering Technology Research Center of Suqian Science and Technology Bureau (Grant No. M201912), the Jiangsu Provincial Science and Technology Department Social Development Project (Grant No. BE2017704) and a Project Funded by the Priority Academic Program Development of Jiangsu Higher Education Institutions.

Conflicts of Interest: The authors declare that they have no conflicts of interest to report regarding the present study.

\section{References}

1. Lu, C. C., Hsu, M. H., Lin, Y. P. (2019). Evaluation of heavy metal leachability of incinerating recycled aggregate and solidification/stabilization products for construction reuse using TCLP, multi-final $\mathrm{pH}$ and EDTA-mediated TCLP leaching tests. Journal of Hazardous Materials, 368, 336-344. DOI 10.1016/j.jhazmat.2019.01.066.

2. Mohd, R. H., Md, M. A., Zulfiqar, A., Putra Jaya, R., El-sergany, M. et al. (2015). Steel slag as a road construction material. Jurnal Teknologi, 73, 33-38.

3. Moura, B. L. R. D., Teixeira, J. E. S. L., Simão, R. A., Khedmati, M., Kim, Y. R. et al. (2020). Adhesion between steel slag aggregates and bituminous binder based on surface characteristics and mixture moisture resistance. Construction and Building Materials, 264, 120685. DOI 10.1016/j.conbuildmat.2020.120685.

4. Gencel, O., Karadag, O., Oren, O. H., Bilir, T. (2021). Steel slag and its applications in cement and concrete technology: A review. Construction and Building Materials, 283, 122783. DOI 10.1016/j. conbuildmat.2021.122783.

5. Yang, L. Y., Wen, T. T., Wang, L. P., Miki, T., Hao, B. et al. (2019). The stability of the compounds formed in the process of removal $\mathrm{Pb}(\mathrm{II}), \mathrm{Cu}(\mathrm{II})$ and $\mathrm{Cd}(\mathrm{II})$ by steelmaking slag in an acidic aqueous solution. Journal of Environmental Management, 231, 41-48. DOI 10.1016/j.jenvman.2018.10.028.

6. Wang, X. B., Li, X. Y., Yan, X., Tu, C., Yu, Z. G. (2021). Environmental risks for application of iron and steel slags in soils in China: A review. Pedosphere, 31(1), 28-42. DOI 10.1016/S1002-0160(20)60058-3.

7. Chen, Z. M., Li, R., Zheng, X. M., Liu, J. X. (2021). Carbon sequestration of steel slag and carbonation for activating RO phase. Cement and Concrete Research, 139, 106271. DOI 10.1016/j.cemconres.2020.106271.

8. Ragipani, R., Escobar, E., Prentice, D., Bustillos, S., Simonetti, D. et al. (2021). Selective sulfur removal from semi-dry flue gas desulfurization coal fly ash for concrete and carbon dioxide capture applications. Waste Management, 121, 117-126. DOI 10.1016/j.wasman.2020.12.007.

9. Chandrasekaran, C. (2017). 10-rubber lining for a sulfur dioxide scrubbing system. Anticorrosive Rubber Lining, 73-76. DOI 10.1016/B978-0-323-44371-5.00010-4.

10. Feng, X. H., Wang, C. Q., Ding, S. M. (2019). Performance of desulfurization ash for the preparation of grouting fire prevention material. Environmental Science and Pollution Research, 26, 19228-19240. DOI 10.1007/s11356019-05248-1.

11. Fang, D., Liao, X., Zhang, X., Teng, A., Xue, X. X. (2018). A novel resource utilization of the calcium-based semidry flue gas desulfurization ash: As a reductant to remove chromium and vanadium from vanadium industrial wastewater. Journal of Hazardous Materials, 342, 436-445. DOI 10.1016/j.jhazmat.2017.08.060. 
12. Navarrete, I., Vargas, F., Martinez, P., Paul, A., Lopez, M. (2021). Flue gas desulfurization (FGD) fly ash as a sustainable, safe alternative for cement-based materials. Journal of Cleaner Production, 283, 124646. DOI 10.1016/j.jclepro.2020.124646.

13. Duong, N., Satomi, T., Takahashi, H. (2021). Potential of corn husk fiber for reinforcing cemented soil with high water content. Construction and Building Materials, 271, 121848. DOI 10.1016/j.conbuildmat.2020.121848.

14. Jauberthie, R., Rendell, F., Rangeard, D., Molez, L. (2010). Stabilisation of estuarine silt with lime and/or cement. Applied Clay Science, 50, 395-400. DOI 10.1016/j.clay.2010.09.004.

15. Xin, D., Chai, X. L., Zhao, W. (2016). Hybrid cement-assisted dewatering, solidification and stabilization of sewage sludge with high organic content. Journal of Material Cycles and Waste Management, 18, 356-365. DOI 10.1007/s10163-014-0337-8.

16. Jongpradist, P., Jumlongrach, N., Youwai, S., Chucheepsakul, S. (2010). Influence of Fly Ash on unconfined compressive strength of cement-admixed clay at high water content. Journal of Materials in Civil Engineering, 22(1), 49-58. DOI 10.1061/(ASCE)0899-1561(2010)22:1(49).

17. Bayesteh, H., Sharifi, M. (2020). Effect of stone powder on the rheological and mechanical performance of cement-stabilized marine clay/sand. Construction and Building Materials, 262, 120792. DOI 10.1016/j. conbuildmat.2020.120792.

18. Wei, L., Chai, S., Zhang, H., Shi, Q. (2018). Mechanical properties of soil reinforced with both lime and four kinds of fiber. Construction and Building Materials, 172, 300-308. DOI 10.1016/j.conbuildmat.2018.03.248.

19. Tran, K., Satomi, T., Takahashi, H. (2017). Study on strength behavior of cement stabilized sludge reinforced with waste cornsilk fiber. International Journal of GEOMATE, 13, 140-147. DOI 10.210/2017.39.28994.

20. Tran, K., Satomi, T., Takahashi, H. (2019). Tensile behaviors of natural fiber and cement reinforced soil subjected to direct tensile test. Journal of Building Engineering, 24, 100748. DOI 10.1016/j.jobe.2019.100748.

21. Ayeldeen, M., Kitazume, M. (2017). Using fiber and liquid polymer to improve the behaviour of cement-stabilized soft clay. Geotextiles and Geomembranes, 45, 592-602. DOI 10.1016/j.geotexmwm.017.05.005.

22. Liu, J. Z., Yu, B., Wang, Q. (2020). Application of steel slag in cement treated aggregate base course. Journal of Cleaner Production, 269, 121733. DOI 10.101/j.jclepo.2020.121733.

23. Moon, D. H., Wazne, M., Cheong, K. H., Chang, Y. Y., Baek, K. et al. (2015). Stabilization of As-, Pb-, and Cucontaminated soil using calcined oyster shells and steel slag. Environmental Science and Pollution Research, 22(14), 11162-11169. DOI 101007/s11356-015-4612-6.

24. Gu, H. H., Hao, Q., Tian, T. (2011). Mitigation effects of silicon rich amendments on heavy metal accumulation in rice (Oryza sativa L.) planted on multi-metal contaminated acidic soil. Chemosphere, 83(9), 1234-1240. DOI 10.1016/j.chemosphere.2011.03.014.

25. Son, J. H., Roh, H., Lee, S. Y., Kim, S. K., Kim, G. H. et al. (2009). Stabilization of heavy metal contaminated paddy soils near abandoned mine with steel slag and $\mathrm{CaO}$. Korea Institute of Soil and Groundwater Environment, 6(14), 78-86.

26. Wang, D., Abriak, N. E., Zentar, R. (2016). Dredged marine sediments used as novel supply of filling materials for road construction. Marine Georesources \& Geotechnology, 35(4), 472-480. DOI 10.10801064119X.2016.119945.

27. Duan, S. Y., Liao, H. Q., Cheng, F. Q., Song, H. P., Yang, H. Q. (2018). Investigation into the synergistic effects in hydrated gelling systems containing fly ash, desulfurization gypsum and steel slag. Construction and Building Materials, 187, 1113-1120. DOI 10.1016/j.conbuildmt.2018.07.241.

28. ASTM (2006). Standard Test Method for Unconfined Compressive Strength of Cohesive Soil. USA: ASTM.

29. Tsakiridis, P., Papadimitriou, G., Tsivilis, S., Koroneos, C. (2008). Utilization of steel slag for portland cement clinker production. Journal of Hazardous Materials, 152, 805-811. DOI 10.1016/j.jhazmat.2007.07.093.

30. Glasser, F. (1997). Fundamental aspects of cement solidification and stabilization. Journal of Hazardous Materials, 52, 151-170. DOI 10.1016/S0304-3894(96)01805-5.

31. Bobet, A., Hwang, J., Johnston, C., Santagata, M. (2011). One-dimensional consolidation behavior of cementtreated organic soil. Canadian Geotechnical Journal, 48, 1100-1115. DOI 10.1139/t11-020. 
JRM, 2022, vol.10, no.3

32. Zhang, R., Santoso, A., Tan, T. S., Phoon, K. K. (2013). Strength of high water-content marine clay stabilized by Low amount of cement. Journal of Geotechnical and Geoenvironmental Engineering, 139, 2170-2181. DOI 10.1061/(ASCE)GT.1943-5606.0000951.

33. Chen, Y. J., He, X. X., Zhang, S. H., Tan, X., Wan, Y. (2020). Strength and microstructure properties of solidified sewage sludge with two types of cement-based binders. Scientific Reports, 10(1), 1-12. DOI 10.1038/s41598-2077701-y.

34. Gu, Z. H., Fang, A. G., Hua, S. D., Zhao, Q. Z., Sun, L. D. et al. (2021). Development of a soil stabilizer for road subgrade based on original phosphogypsum. Journal of Renewable Materials, 9, 253-268. DOI 10.32604/ jrm.2021.011912.

35. Hargis, C., Kirchheim, A., Monteiro, P., Gartner, E. (2013). Early age hydration of calcium sulfoaluminate (synthetic ye'elimite, $\mathrm{C}_{4} \mathrm{~A}_{3} \mathrm{~S}$ ) in the presence of gypsum and varying amounts of calcium hydroxide. Cement and Concrete Research, 48, 105-115. DOI 10.1016/j.cemconres.203.03.001.

36. Shamaa, M., Lavaud, S., Divet, L., Nahas, G., Torrenti, J. M. (2015). Influence of relative humidity on delayed ettringite formation. Cement and Concrete Composites, 58, 14-22. DOI 10.1016/j.cemconcomp.2014.12.013.

37. Tosun, K., Baradan, B. (2010). Effect of ettringite morphology on DEF-related expansion. Cement and Concrete Composites, 32, 271-280. DOI 10.1016/j.cemconcomp.20100.01.002.

38. Cody, A. M., Lee, H., Cody, R. D., Spry, P. (2004). The effects of chemical environment on the nucleation, growth, and stability of ettringite $\left[\mathrm{Ca}_{3} \mathrm{Al}(\mathrm{OH})_{6}\right]_{2}\left(\mathrm{SO}_{4}\right)_{3} \cdot 26 \mathrm{H}_{2} \mathrm{O}$. Cement and Concrete Research, 34, 869-881. DOI 10.1016/j.cemconres.2003.10.023. 